\title{
Becaplermin gel in the treatment of diabetic neuropathic foot ulcers
}

\author{
Nikolaos Papanas \\ Efstratios Maltezos \\ Outpatient Clinic of Obesity, Diabetes \\ and Metabolism at the Second \\ Department of Internal Medicine, \\ Democritus University of Thrace, \\ Greece
}

\begin{abstract}
Diabetic foot ulcers remain a major cause of morbidity. Significant progress has been accomplished in ulcer healing by improved management of both ischemia and neuropathy in the diabetic foot. Nevertheless, there is a vital need for further improvement. Becaplermin gel represents an important therapeutic advance for diabetic neuropathic foot ulcers with adequate blood supply. Randomized controlled trials have shown that it is effective in increasing healing rates. However, this efficacy has not translated to positive clinical experience, and the drug is not widely used. Moreover, becaplermin is an expensive medication. Even though it has repeatedly been estimated as cost-effective, its high cost may be prohibitive for some clinicians, especially in developing countries. Clearly, further work is needed to clarify whether use of becaplermin is justified in everyday clinical practice. Future research also needs to assess the potential room for improvement with becaplermin, for instance by combination with other growth factors or by exploring alternative modes of drug delivery.
\end{abstract}

Keywords: becaplermin, diabetes mellitus, diabetic foot, neuropathy, PDGF

\section{Introduction}

During the last 20 years, the world has witnessed an unparalleled increase in the incidence of diabetes mellitus, which has been identified as a threatening epidemic (Wild et al 2004; Coliaguri et al 2005). Diabetic complications now account for the greater part of diabetes-related morbidity and healthcare costs (Boulton 2004; Bakker et al 2005; Boulton et al 2005). This holds especially true for the diabetic foot (Manes et al 2002; Boulton 2004; Boulton et al 2005). Indeed, diabetes is the major cause of nontraumatic lower-extremity amputations, reducing patient survival (Tentolouris et al 2004) and inflicting an enormous financial burden on society (Boulton et al 2005). It is not long ago that the International Working Group on the Diabetic Foot estimated the loss of a foot or leg attributable to diabetes every 30 seconds in the world (Bakker et al 2005). Naturally, amputations are associated with substantial direct (ie, hospitalization and medication) as well as indirect (ie, loss of working days) costs (Boulton 2004; Boulton et al 2005).

It is now beyond dispute that the vast majority of amputations result from prior ulceration (Boulton 2004; Boulton et al 2005). Diabetic foot ulcers have a complex pathophysiology and are notoriously difficult to heal (Boulton 2004; Bakker et al 2005; Boulton et al 2005; Falanga 2005). The strategy to improve healing rates is based on the management of peripheral arterial disease, relief of high-pressure areas, aggressive debridement, and infection control (Watkins 2003; Boulton 2004; Edmonds 2004). At the same time, new treatments (growth factors, bioengineered skin substitutes, extracellular matrix proteins, and various other products) are continuously being explored (Jeffcoate et al 2004; Petrova and Edmonds 2006). This article reviews the use of becaplermin in the treatment of diabetic neuropathic foot 
ulcers. Becaplermin is recombinant platelet-derived growth factor commercially available as a gel form of $100 \mu \mathrm{g} / \mathrm{g}$ becaplermin. At the moment, it represents the only growth factor approved by American and European authorities for use in the treatment of foot ulceration.

\section{Diabetic foot ulcers}

Overall, one out of four diabetic patients runs the risk of developing foot ulceration in his lifetime (Reiber and Ledoux 2002). Foot ulcers result from the composite interaction of three major entities: ischemia, neuropathy, and infection (Reiber et al 1999; Boulton 2004; Edmonds 2004; Edmonds et al 2004a; Singh et al 2005). Ischemia is ascribed to peripheral arterial disease, which is exceedingly frequent in diabetes, and leads to poor nutrient supply to peripheral tissue (Sumpio et al 2003; Edmonds 2004). Neuropathy deprives patients of protective sensation, so that trauma (such as induced by stepping on a sharp object or, simply, due to ill-fitting shoes) may be unrecognized, leading to continuing tissue destruction (Reiber et al 1999; Boulton et al 2004; Edmonds 2004; Singh et al 2005). Moreover, it leads to various foot deformities, resulting in abnormal focal pressure distribution on the plantar aspect of the foot (Reiber et al 1999; Boulton et al 2004; Edmonds 2004). Accordingly, some plantar sites have very high pressures and can easily develop ulcers (Reiber et al 1999; Boulton et al 2004; Edmonds 2004). Ultimately, more than half of chronic foot ulcers become infected (Pecoraro 1991). Infection is usually polymicrobial, with a combination of Gram-positive cocci, Gram-negative bacteria, and anaerobes, and may rapidly lead to necrosis (Edmonds 2004; Edmonds et al 2004b).

A clinically useful classification is into two categories: neuroischemic and neuropathic foot ulcers (Watkins 2003; Edmonds et al 2004a). In the former, neuropathy and ischemia coexist. The ulcer is usually located on the margins of the foot, has irregular shape and is typically painful, although peripheral neuropathy in some patients reduces or obviates pain. The foot is not warm, but may be cold and pulseless (Watkins 2003; Edmonds et al 2004a). The latter is most commonly found in high-pressure areas, notably prominent metatarsal heads and apices of toes (Watkins 2003; Edmonds et al 2004a). It is usually painless, surrounded by heavy callus formation and may be somewhat circular with a raised rim. The foot is warm, with intact pulses, while sensation is diminished (Watkins 2003; Boulton et al 2004; Edmonds et al 2004a). This distinction is of vital importance, because treatment differs according to etiology (Watkins 2003; Edmonds et al 2004a).

\section{Overview of normal healing}

Normal healing is a complex process requiring the collaboration of numerous cells involved in the four overlapping phases of the healing cascade (Kirsner and Bogensberger 2002; Jeffcoate et al 2004; Falanga 2005). These phases are, by tradition, classified as hemostasis, inflammation, migration/proliferation (otherwise known as maturation), and remodelling (Table 1) (Kirsner and Bogensberger 2002; Jeffcoate et al 2004; Falanga 2005) and will be very briefly described below. Immediately after injury, vasoconstriction and platelet activation occur (hemostasis) (Jeffcoate et al 2004; Falanga 2005). Platelets are the initiators of the clotting cascade, but they also release growth factors (including platelet-derived growth factor, PDGF) and cytokines to attract other cells required for healing. In the next phase, inflammatory cells (mainly neutrophils and macrophages, but also lymphocytes) enter the wound site by chemotaxis (Jeffcoate et al 2004; Falanga 2005). Neutrophils eliminate necrotic debris; macrophages remove bacteria and necrotic tissue, and they secrete growth factors to facilitate continuation of healing; lymphocytes have a less clearly defined role. In the subsequent phase, migration/proliferation, wound contraction predominates (Jeffcoate et al 2004; Falanga 2005). Tissue integrity is restored by fibroplasia, new vessel formation (neovascularization), and skin re-epithelialization (Jeffcoate et al 2004; Falanga 2005). Finally, remodeling is a slow dynamic process, in which cell density and vascularization are diminished, while the total amount and the tensile strength of collagen increase (Jeffcoate et al 2004; Falanga

Table I Overview of the phases of normal wound healing (Kirsner and Bogensberger 2002; Jeffcoate et al 2004; Falanga 2005)

\begin{tabular}{|c|c|c|}
\hline Phase & Main cell types & Main activity \\
\hline Coagulation & Platelets & $\begin{array}{l}\text { Vasoconstriction, clot } \\
\text { formation, secretion of } \\
\text { growth factors, and } \\
\text { cytokines }\end{array}$ \\
\hline Inflammation & $\begin{array}{l}\text { Leukocytes (neutrophils, } \\
\text { monocytes, macrophages) }\end{array}$ & $\begin{array}{l}\text { Chemotaxis of } \\
\text { inflammatory cells, } \\
\text { eradication of bacteria, } \\
\text { and necrotic debris }\end{array}$ \\
\hline $\begin{array}{l}\text { Migration/ } \\
\text { proliferation* }\end{array}$ & $\begin{array}{l}\text { Keratinocytes, fibroblasts, } \\
\text { endothelial cells }\end{array}$ & $\begin{array}{l}\text { New vessel formation, } \\
\text { fibroplasia }\end{array}$ \\
\hline Remodeling & Fibroblasts & $\begin{array}{l}\text { Wound contraction, } \\
\text { realignment of collagen } \\
\text { fibers to increase tensile } \\
\text { strength, scarring }\end{array}$ \\
\hline
\end{tabular}

Notes: *Otherwise known as maturation. 
2005). Moreover, collagen fibers are progressively realigned and may lead to a variable amount of scarring (Kirsner and Bogensberger 2002; Jeffcoate et al 2004; Falanga 2005).

\section{Impaired healing in diabetes}

Healing of foot ulcers is characteristically impaired in diabetes (Edmonds 2004; Jeffcoate et al 2004; Falanga 2005). Therefore, patients often present with chronic, refractory, or recurrent foot ulcers (Edmonds 2004; Jeffcoate et al 2004). The detrimental effect of diabetes on healing may be described as being exerted at two levels. The first level comprises factors extrinsic to the wound itself, while the second level consists of intrinsic factors. Extrinsic factors can be summarized as the aforementioned triad of peripheral arterial occlusive disease, neuropathy, and infection (Edmonds 2004; Jeffcoate et al 2004). Naturally, peripheral arterial occlusive disease results in diminished oxygen supply to the components of the wound (Boulton 2004; Edmonds 2004). If ischemia is severe, it may even prevent intravenously administered antibiotics from achieving adequate concentration in the wound (Edmonds et al 2004b). Peripheral autonomic neuropathy may lead to disruption of the neurogenic control of small blood vessels, thereby resulting in diminished inflammatory response and impaired wound healing (Parkhouse and Le Quesne 1988; Edmonds et al 2004b). Infection complicates diabetic foot ulceration and aggravates cellular hypoxia by raising metabolic demands and by causing a neutrophilic vasculitis (Edmonds 2004; Jeffcoate et al 2004).

Intrinsic factors are now being increasingly investigated. It is thought that they affect local growth factors and miscellaneous wound healing constituents. Diabetic foot ulcers have been shown to exhibit abnormal or reduced expression of growth factors (Jeffcoate et al 2004; Falanga 2005). Diminished biologic action of growth factors due to nonenzymatic glycosylation is also a contributory factor (Jeffcoate et al 2004). Some chronic diabetic foot ulcers also do not respond to local growth factors (Jude et al 2002; Black et al 2003). At a cellular level, reduced neutrophil chemotaxis, defective fibroblast action, and impaired capacity of other cell populations for migration and proliferation (Jude et al 2002; Jeffcoate et al 2004; Blakytny and Jude 2006) have been found. Finally, poor co-ordination of matrix metalloproteases with their tissue inhibitors exacerbates the impairment of healing (Jeffcoate et al 2004; Blakytny and Jude 2006).

Interestingly, hyperglycemia substantially affects both extrinsic and intrinsic factors. Not only has impaired metabolic control been associated with increased prevalence of diabetic complications, notably neuropathy and vascular disease (Boulton 2004; Bakker et al 2005; Boulton et al 2005), but it also impacts on the healing process itself (Papanas and Maltezos 2007). Indeed, the magnitude of hyperglycemia adds to the perturbation of the normal healing cascade. This negative effect is mediated via impaired function of intrinsic healing factors and via disordered participation of the cellular components of healing (Blakytny and Jude 2006). The recognition of this effect of hyperglycemia has obvious implications in clinical practice, which emphasizes the need for optimizing glycemic control.

\section{Overview of the treatment for diabetic foot ulcers}

Treatment of diabetic foot ulcers needs to address the three major causal factors: ischemia, neuropathy, and infection (Watkins 2003; Boulton 2004; Edmonds 2004). In the neuroischemic foot, it is imperative to diagnose ischemia immediately and to restore normal blood flow to the limb. This can be achieved either surgically (bypass graft surgery) or intravascularly (percutaneous transluminal angioplasty) as required (Sumpio et al 2003; Edmonds 2004). In the neuropathic foot, the ulcerated area needs to be off-loaded with casts and cushioning insoles (Boulton 2004; Edmonds 2004). Off-loading is combined with surgical debridement, which has been documented to promote granulation and wound closure (Edmonds 2004; Steed 2004). In both neuroischemic and neuropathic ulcers, a high index of suspicion for the diagnosis of infection is necessary to enable timely institution of antibiotics, choosing initially broad-spectrum agents and, subsequently, guided by appropriate cultures. These are usually swab cultures, although some authorities prefer deep tissue specimens (Edmonds 2004; Edmonds et al 2004b). Advances in these treatment modalities have led to improvement in healing rates (Edmonds 2004). However, a significant number of ulcers (as high as $49 \%$ ) still may fail to heal (Margolis et al 2005a), indicating the need for further improvement.

\section{Why use growth factors to promote healing?}

Growth factors have been shown to be omnipresent throughout the healing process (Köveker 2000; Cavanagh et al 2005). They act by binding to specific receptors in the plasma membranes of target cells, thereby activating signal transduction mechanisms (Köveker 2000; Cavanagh et al 2005). At the cellular level, growth factors mediate macrophage migration, neovascularization, collagen synthesis, fibroblast 
proliferation, as well as final re-epithelialization (Papanas and Maltezos 2007). Importantly, each growth factor acts on several cell lines, and this interaction enhances healing (Köveker 2000; Cavanagh et al 2005). The need to improve the aforementioned cellular functions has led to the ongoing exploration of several growth factors (Köveker 2000; Cavanagh et al 2005). The rationale for this investigation is that while the restoration of a normal healing cascade may be elusive, any improvement in healing rates obtained with growth factors would be useful (Köveker 2000; Margolis et al 2005a).

The main growth factors involved in healing are: PDGF, fibroblast growth factor (FGF), vascular endothelial growth factor (VEGF), insulin-like growth factors $\left(\mathrm{IGF}_{1}, \mathrm{IGF}_{2}\right)$, epidermal growth factor (EGF), and transforming growth factor $\beta$ (TGF- $\beta$ ) (Köveker 2000; Jeffcoate 2004; Falanga 2005). To date, only PDGF has been approved by the US Food and Drug Administration and European authorities (Papanas and Maltezos 2007). Other growth factors include granulocyte-colony stimulating factor (GCSF) and nerve growth factor (NGF) (Papanas and Maltezos 2007). Initially, GCSF yielded very good results in infected diabetic foot ulcers without severe ischemia, but these were not replicated in the following studies, so that its clinical utility is rather questionable (Bennett et al 2003; Cruciani et al 2005; Papanas and Maltezos 2007). Experience with the other growth factors remains very limited (Papanas and Maltezos 2007).

\section{PDGF: a protagonist in healing}

Platelet-derived growth factor is mainly secreted by the platelets' $\alpha$-granule, but it is also produced by other cells involved in early wound healing, ie, macrophages, endothelial cells, fibroblasts, and keratinocytes (Papanas and Maltezos 2007). PDGF is a powerful chemoattractant and mitogen, exerting its action on fibroblasts, smooth muscle cells, and endothelial cells (Papanas and Maltezos 2007). It also induces production of fibronectin and hyaluronic acid. There is a synergistic effect between PDGF and EGF, as well as TGF- $\beta$, and so PDGF has a pivotal role at all stages of wound healing (Nagai and Embil 2002; Papanas and Maltezos 2007).

PDGF is a dimer consisting of $\mathrm{A}$ and/or $\mathrm{B}$ chains, held together by a disulfide bond. Three isomers (AA, BB, and $\mathrm{AB})$ have been isolated. The most common and potent isomer is the BB isomer (Nagai and Embil 2002; Papanas and Maltezos 2007). Therefore, this isomer is the one used in the management of foot ulcers (Nagai and Embil 2002; Papanas and Maltezos 2007).
At present, recombinant PDGF is produced by DNA technology via incorporation of the gene for the $\beta$-chain of human PDGF into the yeast Saccharomyces cerevisiae. The resultant homodimeric protein, becaplermin, has a biological activity similar to the endogenous PDGF-BB (Papanas and Maltezos 2007). A gel form of $100 \mu \mathrm{g} / \mathrm{g}$ becaplermin (Regranex $^{\circledR}$ gel; Ortho-McNeil Pharmaceutical, Inc, Titusville, NJ, USA) has been approved by the US Food and Drug Administration for the treatment of diabetic neuropathic ulcers with adequate peripheral circulation (Papanas and Maltezos 2007).

\section{Efficacy of becaplermin gel in neuropathic diabetic foot ulcers}

The efficacy of becaplermin gel in the management of neuropathic ulcers has been documented by a number of randomized controlled trials, reviewed in more detail elsewhere (Papanas and Maltezos 2007). In these, 922 patients were studied in total (Steed 1995; Smiell 1998; Smiell et al 1999; Wieman et al 1998; Wieman 1998; D'Hemercourt et al 1998; Embil et al 2000). Steed conducted the first randomized, double-blind placebocontrolled trial (Steed 1995). He enrolled 118 patients, randomized to topical application of $30 \mu \mathrm{g} / \mathrm{g}$ becaplermin $(\mathrm{N}=61)$ or placebo $(\mathrm{N}=57)$. At the end of the study, $48 \%(29 / 61)$ of ulcers healed in the becaplermin group vs. $25 \%(14 / 57)$ in the placebo group $(\mathrm{p}=0.01)$ (Steed 1995). There was also a non-significant trend $(\mathrm{p}=0.09)$ for a greater median reduction in wound area in the becaplermin group (98.8\%) as compared with the placebo group $(82.1 \%)$.

Wieman and colleagues (1998) conducted a phase III randomized double-blind placebo-controlled trial on the efficacy and safety of becaplermin gel $30 \mu \mathrm{g} / \mathrm{g}(\mathrm{N}=132)$ vs. becaplermin gel $100 \mu \mathrm{g} / \mathrm{g}(\mathrm{N}=123)$ vs. placebo $(\mathrm{N}=127)$ (Wieman et al 1998). This work showed that becaplermin gel $100 \mu \mathrm{g} / \mathrm{g}$ added to standard wound care significantly increased healing rates and decreased time to complete healing (Wieman et al 1998). Healing rates were $49.5 \%(61 / 123)$ in patients receiving becaplermin gel $100 \mu \mathrm{g} / \mathrm{g}, 36.3 \%$ (48/132) in those receiving becaplermin gel $30 \mu \mathrm{g} / \mathrm{g}$, and $34.6 \%$ (44/127) in those receiving placebo. There was a significant difference $(\mathrm{p}=0.007)$ between high-dose becaplermin and placebo (Wieman et al 1998).

D'Hemercourt and colleagues (1998) compared three treatment regimens, ie, good wound care alone $(\mathrm{N}=68)$, topical carboxymethylcellulose gel $(\mathrm{N}=70)$, and becaplermin gel $100 \mu \mathrm{g} / \mathrm{g}$ added to standard wound 
care $(\mathrm{N}=34)$. This study was statistically underpowered. However, becaplermin-treated patients did achieve a slightly higher healing rate $(44.1 \%)$ in comparison with carboxymethylcellulose-treated patients $(35.7 \%)$ and those receiving standard wound care alone (22\%) (D'Hemercourt et al 1998).

A multi-center phase IIIB open-label study examined the efficacy and safety of becaplermin gel $100 \mu \mathrm{g} / \mathrm{g}$ in 134 patients (Embil et al 2000). It was shown that as high as $57.5 \%$ of ulcers managed to heal with a mean time to wound closure of 63 days and a $21 \%$ six-month recurrence rate (Embil et al 2000).

Smiell and colleagues (1999) carried out a combined analysis based on all 922 patients recruited in the aforementioned studies (Steed 1995; Wieman et al 1998; D'Hemercourt et al 1998; Embil et al 2000). This analysis provided evidence for a significant beneficial effect of becaplermin on healing. Indeed, becaplermin gel $100 \mu \mathrm{g} / \mathrm{g}$ significantly $(\mathrm{p}=0.0007)$ increased the likelihood of complete wound healing in comparison with placebo by $39 \%$ (50\% vs. $36 \%$, respectively). The drug also significantly $(\mathrm{p}=0.01)$ decreased the time to heal as compared with placebo by $30 \%$ (14.1 weeks vs. 20.1 weeks, respectively) (Smiell et al 1999).

Table 2 summarizes the clinical trials on becaplermin. In all studies, inclusion criteria were: a) chronic foot ulcer of duration $\geq 8$ weeks); b) adequate arterial perfusion as documented by Ankle-Brachial Pressure
Index $>0.70$ and/or transcutaneous partial pressure of oxygen $\geq 30 \mathrm{mmHg}$; c) absence of infection (Papanas and Maltezos 2007).

\section{Safety of becaplermin gel in neuropathic diabetic foot ulcers}

In all clinical trials, the safety profile of becaplermin has consistently been found excellent, comparable with that of placebo (Papanas and Maltezos 2007). The clinical safety of the drug has also been specifically examined by Smiell (1998). It was demonstrated that rash occurred in $2 \%$ of becaplermin-treated patients and in $1 \%$ of those receiving placebo. Similarly, cardiovascular, respiratory, musculoskeletal and central or peripheral nervous system disorders did not differ between becaplermin- and placebo-treated subjects. Moreover, there were no neutralizing antibodies against becaplermin (Smiell 1998).

\section{Cost-Effectiveness of becaplermin gel in neuropathic diabetic foot ulcers}

Several authors have examined the cost-effectiveness of becaplermin (Persson et al 2000; Ghatnekar et al 2001; Kantor and Margolis 2001; Albert 2002; Sibbald et al 2003). The drug has been shown to be cost-effective in Sweden (Persson et al 2000), in four European countries

Table 2 Clinical trials of PDGF in diabetic foot ulcers. Copyright @ 2007 SAGE Publications. Reproduced with permission from Papanas N, Maltezos E. 2007. Growth factors in the treatment of diabetic foot ulcers: new technologies, any promises? Int J Low Extrem Wounds, 6:37-53

\begin{tabular}{|c|c|c|c|c|}
\hline \multicolumn{5}{|c|}{ Platelet-derived growth factor } \\
\hline Author & Year & Study design & Comparison & Main findings \\
\hline Steed & 1995 & $\begin{array}{l}\text { Double blind placebo } \\
\text { controlled }\end{array}$ & $\begin{array}{l}\text { Topical PDGF gel } 30 \mu g / g \text { vs. } \\
\text { placebo }\end{array}$ & $\begin{array}{l}\text { Complete ulcer closure at } 20 \\
\text { weeks: } 48 \% \text { vs. } 25 \%, p=0.01\end{array}$ \\
\hline Wieman & 1998 & $\begin{array}{l}\text { Double blind placebo } \\
\text { controlled }\end{array}$ & $\begin{array}{l}\text { Topical PDGF gel } 100 \mu g / g \\
\text { vs. } 30 \text { vs. } \mu g / g \text { vs. placebo }\end{array}$ & $\begin{array}{l}\text { Complete ulcer closure: } 49.5 \% \\
\text { vs. } 36 \% \text { vs. } 35 \%, p=0.007 \\
\text { Mean time to heal: } 86 \text { days ( } 100 \\
\mu g / g) \text { vs. } 127 \text { days (placebo) }\end{array}$ \\
\hline D'Hemercourt & 1998 & $\begin{array}{l}\text { Randomized double-blind } \\
\text { placebo-controlled }\end{array}$ & $\begin{array}{l}\text { Topical PDGF gel I } 00 \mu \mathrm{g} / \mathrm{g} \\
\text { vs. carboxymethylcellulose } \\
\text { gel vs. good ulcer care }\end{array}$ & $\begin{array}{l}\text { Complete ulcer closure: } 44.1 \% \\
\text { vs. } 35.7 \% \text { vs. } 22 \%\end{array}$ \\
\hline Embil & 2000 & Phase IIIB open-label & $\begin{array}{l}\text { Safety of topical PDGF gel } \\
100 \mu \mathrm{g} / \mathrm{g}\end{array}$ & $\begin{array}{l}\text { Complete ulcer closure: } 57.5 \% \\
\text { Mean time to heal: } 63 \text { days }\end{array}$ \\
\hline Smiell & 1999 & Meta-analysis* & $\begin{array}{l}\text { Topical PDGF gel } 100 \mu g / g \\
\text { vs. placebo }\end{array}$ & $\begin{array}{l}\text { Complete ulcer closure: } 50 \% \text { vs. } \\
36 \%, p=0.0007 \\
\text { Mean time to heal: } 14.1 \text { weeks } \\
\text { vs. } 20.1 \text { weeks, } p=0.01\end{array}$ \\
\hline
\end{tabular}

Notes: *Meta-analysis of the studies by Steed (1995), Wieman (1998), D’Hemercourt (1998), and Embil (2000). 
(Sweden, Switzerland, UK, and France) (Ghatnekar et al 2001) and in the USA (Kantor and Margolis 2001). In the USA, the addition of becaplermin is associated with an initial higher cost, but this effectively reduces expenses resulting from more prolonged treatment, namely office visits and dressings, as well as complication rates (Albert 2002). Indeed, adding up to 20 weeks of becaplermin to best medical care over 12 months resulted in 26 fewer ulcer-days per patient, equating to an avoided costeffectiveness ratio of US\$6 per ulcer-day (Sibbald et al 2003). A cost-effectiveness study of becaplermin in other parts of the world, including developing countries, is missing (Papanas and Maltezos 2007).

\section{Becaplermin gel in actual clinical practice: expectations still not met}

Although becaplermin has been shown to significantly improve healing rates in small randomized controlled trials, this efficacy has not yet translated to positive clinical experience (Papanas and Maltezos 2007). This discrepancy may be ascribed to the fact that randomized trials are conducted under tightly controlled conditions, whereas clinicians encounter patients in actual practice, rather than in the ideal world (Papanas and Maltezos 2007). Consequently, efficacy of the drug under study in the setting of a controlled trial does not necessarily translate into effectiveness of the same drug in everyday clinical situation. This prompted Margolis and colleagues (2005b) to examine the effectiveness of becaplermin in actual clinical practice. Their study included 24,898 subjects with neuropathic foot ulceration between 1998 and 2004, of whom 2394 (9.6\%) received becaplermin (Margolis et al 2005b). Healing rates were $33.5 \%$ and $25.8 \%$ in the becaplermin and control group respectively $(\mathrm{p}<0.0001)$ (Margolis et al 2005b). Accordingly, becaplermin increased the likelihood of healing by $32 \%(R R=1.32)$. Moreover, amputation rates were significantly $(\mathrm{p}<0.0001)$ lower in the becaplermin (4.9\%) than in the control group (6.4\%), despite the fact that patients receiving becaplermin had considerable adverse risk factors for healing (increased wound duration and size, increased wound grade at initial visit) (Margolis et al 2005b).

The study by Margolis and colleagues (2005b) again suggested that becaplermin should be expected to improve healing rates in practice. However, this expectation has not been met, so that the drug is still not widely used. In line with this clinical wisdom, the International Working Group on the Diabetic Foot has in a very recent international consensus statement suggested that evidence justifying the use of becaplermin remains to be confirmed (International Working Group on the Diabetic Foot 2007). Obviously, further improvement is required to utilize the beneficial potential of becaplermin in everyday clinical situations.

\section{Implications for further improvement with becaplermin}

The recognition that routine clinical experience with becaplermin in the management of diabetic foot ulcers has been less successful than hoped for (International Working Group on the Diabetic Foot 2007; Papanas and Maltezos 2007) has led to the exploration of potential areas of improvement with the use of this agent. It has been hypothesized that application of a growth factor in a liquid or gel form might not ensure availability to the healing cells in the wound site (Margolis et al 2000a). Hence, alternative modes of growth factor delivery have been explored (Eming et al 1999; Liechty et al 1999; Breitbart et al 2003; Man et al 2005). Encapsulation of growth factors into red blood cells or microspheres, application of skin substitutes overexpressing growth factors, genetic manipulation, and intraarterial growth factor infusion represent the most important alternatives (Eming et al 1999; Liechty et al 1999; Breitbart et al 2003; Man et al 2005). Most of the work with alternative modes of growth factor delivery is still experimental, and clinical experience is eagerly awaited (Papanas and Maltezos 2007).

Combination of becaplermin with other growth factors to enhance healing is a further attractive notion (Papanas and Maltezos 2007). This combination is justified on the basis of the naturally occurring interaction between growth factors during normal healing (Papanas and Maltezos 2007). A study of the effect of growth factors on healing in fullthickness skin wounds created on the backs of diabetic mice has, indeed, provided evidence for a synergistic action of the PDGF and TGF- $\alpha$ combination (Brown et al 1994).

Additionally, the option of longer exposure time of the wound to becaplermin to optimize the frequency of drug application and dressing changes is also highly interesting (Castronuovo et al 1998). However, this possibility remains hitherto unexplored (Papanas and Maltezos 2007).

Finally, it should not escape our notice that becaplermin has been mostly studied in patients with type 2 diabetes. This type of diabetes is now showing an unprecedented epidemic across the world (Wild et al 2004; Coliaguri et al 2005). Thus, the greater proportion of foot ulcers is encountered in patients with type 2 diabetes (Boulton 2004; Bakker et al 2005; Boulton et al 2005). However, it might be useful to examine if 
there is any difference in the efficacy of becaplermin between patients with type 1 and those with type 2 diabetes.

\section{Conclusions}

The diabetic foot continues to be a major cause of morbidity across the world, and there is a fundamental need to improve the outcomes (Bakker et al 2005; Papanas et al 2006a). The development of growth factors to promote wound healing represents an important step forward, but there is still a long way to go. Becaplermin is the only growth factor currently approved for use in diabetic foot ulcers (Papanas and Maltezos 2007). Nonetheless, it may only be used in neuropathic ulcers with adequate peripheral circulation (Papanas and Maltezos 2007). More importantly, it is a widespread clinical impression that its success in everyday practice has been less triumphant than might have been anticipated on the grounds of randomized controlled trials (International Working Group on the Diabetic Foot 2007; Papanas and Maltezos 2007). Last but not least, becaplermin is an expensive medication. Even though it has repeatedly been estimated as cost-effective in the Western world, its high cost may be prohibitive in developing countries, which are responsible for a great part of the global burden of the diabetic foot (Bakker et al 2005; Boulton et al 2005).

Clearly, further work is needed to render becaplermin a more effective tool. Some of the potential areas of improvement have already been identified as improved drug delivery to the ulcer and combination therapy with other growth factors to achieve a synergistic effect (Brown et al 1994; Castronuovo et al 1998; Man et al 2005). Of equal importance is the necessity for a more precise definition of the role of becaplermin in the overall treatment strategy for the diabetic foot (Papanas and Maltezos 2007). Clinicians need evidence-based guidelines specifying when to use standard care and when to consider the use of this agent. Should they, for instance, only use becaplermin in ulcers that have already proved refractory to established treatment or should they try to predict which ulcers are more difficult to heal (Margolis et al 2000b) and might benefit from earlier initiation of growth factor treatment?

Finally, it should not be underestimated that the use of becaplermin, as indeed of every new therapeutic modality, should not be practiced alone, but be incorporated in a holistic strategic approach. Essentially, only multidisciplinary foot clinics have demonstrated that the reduction of lower-limb amputations is possible (Edmonds et al 1986; Holstein and Sorensen 1999; Holstein et al 2000, 2001; van Houtum et al 2004). Knowledge needs to be implemented more vigorously, coupled with constant education of patients and physicians alike, emphasizing on primary and secondary prevention (Papanas et al 2005, 2006b). Numerous obstacles to effective foot care still prevail and need to be abolished to reduce amputations (van Houtum 2005; Papanas et al 2006b).

\section{Disclosure}

The authors have no conflict of interest in relation to the products discussed.

\section{References}

Albert S. 2002. Cost-effective management of recalcitrant diabetic foot ulcers. Clin Podiatr Med Surg, 19:483-91.

Bakker K, Foster AVM, van Houtoum WH, et al. (eds). 2005. Time to act. The Netherlands, International Diabetes Federation and International Working Group of the Diabetic Foot.

Bennett SP, Griffiths GD, Schor AM, et al. 2003. Growth factors in the treatment of diabetic foot ulcers. Br J Surg, 90:133-46.

Black E, Vibe-Pedersen J, Jorgensen LN, et al. 2003. Decrease of collagen deposition in wound repair in type 1 diabetes independent of glycemic control. Arch Surg, 138:34-40.

Blakytny R, Jude E. 2006. The molecular biology of chronic wounds and delayed healing in diabetes. Diabet Med, 23:594-608.

Boulton AJM. 2004. The diabetic foot: from art to science. The 18th Camillo Golgi lecture. Diabetologia, 47:1343-53.

Boulton AJM, Kirsner RS, Vileikyte L. 2004. Neuropathic diabetic foot ulcers. NEngl J Med, 351:48-55.

Boulton AJM, Vileikyte L, Ragnarson-Tennvall G, et al. 2005. The global burden of diabetic foot disease. Lancet, 366:1719-24.

Breitbart AS, Laser J, Parrett B, et al. 2003. Accelerated diabetic wound healing using cultured dermal fibroblasts retrovirally transduced with the platelet-derived growth factor B gene. Ann Plast Surg, 51:409-14.

Brown RL, Breeden MP, Greenhalgh DG. 1994. PDGF and TGF- $\alpha$ act synergistically to improve wound healing in the genetically diabetic mouse. J Surg Res, 56:562-70.

Castronuovo JJ, Ghobrial I, Giusti AM, et al. 1998. Effects of chronic wound fluid on the structure and biological activity of becaplermin (rhPDGFBB) and becaplermin gel. Am J Surg, 176(Suppl 2A):61S-67S.

Cavanagh PR, Lipsky BA, Bradbury AW, et al. 2005. Treatment for diabetic foot ulcers. Lancet, 366:1725-35.

Coliaguri S, Borch-Johnsen K, Glümer C, et al. 2005. There really is an epidemic of type 2 diabetes. Diabetologia, 48:1459-63.

Cruciani M, Lipsky BA, Mengoli C, et al. 2005. Are granulocyte colonystimulating factots beneficial in treating diabetic foot infections? Diabetes Care, 28:454-60.

D'Hemercourt PA, Smiell JM, Karim MR. 1998. Effect of sodium carbomethylcellulose aqueous-based gel vs. becaplermin gel in patients with non-healing lower extremity diabetic ulcers. Wounds, 10:69-75.

Edmonds ME, Blundell MP, Morris ME, et al. 1986. Improved survival of the diabetic foot: the role of a specialized foot clinic. $Q \mathrm{~J} \mathrm{Med}$, 60:763-71.

Edmonds M. 2004. The diabetic foot, 2003. Diabetes Metab Res Rev, 20(Suppl 1):S9-S12.

Edmonds ME, Foster AVM, Sanders LJ. 2004a. Stage 3: the ulcerated foot. In: Edmonds ME, Foster AVM, Sanders LJ (eds). A Practical Manual of diabetic footcare. Oxford: Blackwell, pp. 62-101.

Edmonds ME, Foster AVM, Sanders LJ. 2004b. Stage 4: the infected foot. In: Edmonds ME, Foster AVM, Sanders LJ (eds). A Practical Manual of diabetic footcare. Oxford: Blackwell, pp. 102-40.

Embil JM, Papp K, Sibblad G, et al. 2000. Recombinant human plateletderived growth factor-BB (becaplermin) for healing chronic lower extremity diabetic ulcers: an open-label clinical evaluation of safety. Wound Rep Reg, 8:162-8. 
Eming SA, Whitsitt JS, He L, et al. 1999. Particle-mediated gene transfer of PDGF isoforms promotes wound repair. J Invest Dermatol, 112:297-302.

Falanga V. 2005. Wound healing and its impairment in the diabetic foot. Lancet, 366:1736-43.

Ghatnekar O, Persson U, Willis M, et al. 2001. Cost effectiveness of becaplermin in the treatment of diabetic foot ulcers in four European countries. Pharmacoeconomist, 19:767-78.

Holstein PE, Sorensen S. 1999. Limb salvage experience in a multidisciplinary diabetic foot unit. Diabetes Care, 22(Suppl 2):B97-103.

Holstein P, Ellitsgaard N, Olsen BB, et al. 2000. Decreasing incidence of major amputations in people with diabetes. Diabetologia, 43:844-7.

Holstein P, Ellitsgaard N, Bornefeld Olsen B, et al. 2001. Decreasing incidence of major amputations in people with diabetes. VASA, 58:28-31.

International Working Group on the Diabetic Foot. 2007. International consensus on the diabetic foot and practical guidelines on the management and prevention of the diabetic foot. Brussels, Belguim: International Working Group on the Diabetic Foot.

Jeffcoate W, Price P, Harding KG. 2004. Wound healing and treatments for people with diabetic foot ulcers. Diabetes Metab Res Rev, 20(Suppl 1):S78-S89.

Jude EB, Blakytny R, Bulmer J, et al. 2002. Transforming growth factorbeta 1, 2, 3 and receptor type I and II in diabetic foot ulcers. Diabet Med, 19:440-7.

Kantor J, Margolis DJ. 2001. Treatment options for diabetic neuropathic foot ulcers: a cost-effectiveness analysis. Dermatol Surg, 27:347-51.

Kirsner RS, Bogensberger G. 2002. The normal process of healing. In: Kloth LC, McCulloch JM (eds). Wound healing alternatives in management. Philadelphia: FA: Davis, pp. 3-34.

Köveker GB. 2000. Growth factors in clinical practice. Int J Clin Pract, 54:590-3.

Liechty KW, Nesbit M, Herlyn M, et al. 1999. Adenoviral-mediated overexpression of platelet-derived growth factor-B corrects ischaemic impaired wound healing. J Invest Dermatol, 113:375-83.

Man LX, Park JC, Terry MJ, et al. 2005. Lentiviral gene therapy with platelet-derived growth factor B sustains acclerated healing of diabetic wounds over time. Ann Plast Surg, 55:81-6.

Manes C, Papazoglou N, Sossidou E, et al. 2002. Prevalence of diabetic neuropathy and foot ulceration: identification of potential risk factors - a population-based study. Wounds, 14:11-15.

Margolis DJ, Crombleholme T, Herlyn M. 2000a. Clinical protocol: Phase I trial to evaluate the safety of H5.020CMV.PDGF-B for the treatment of a diabetic insensate foot ulcer. Wound Rep Reg, 8:480-93.

Margolis DJ, Kantor J, Santanna J, et al. 2000b. Risk factors for delayed healing of neuropathic diabetic foot ulcers. Arch Dermatol, 136:1531-5

Margolis DJ, Allen-Taylor L, Hoffstad O, et al. 2005a. Healing diabetic neuropathic foot ulcers: are we getting better? Diabet Med, 22:172-6.

Margolis DJ, Bartus C, Hoffstad O, et al. 2005b. Effectiveness of recombinant human platelet-derived growth factor for the treatment of diabetic neuropathic foot ulcers. Wound Rep Reg, 13:531-6.

Nagai MK, Embil JM. 2002. Becaplermin: recombinant platelet-derived growth factor, a new treatment for healing diabetic foot ulcers. Expert Opin Biol, 2:211-18.

Papanas N, Maltezos E, Edmonds A, et al. 2005. The Ten Commandments of the diabetic foot. BMJ, 331:1497.

Papanas N, Maltezos E, Edmonds M. 2006a. St. Vincent declaration after 15 years or who cleft the devil's foot? VASA, 35:3-4.
Papanas N, Maltezos E, Edmonds M. 2006b. The diabetic foot: a plea for the elementary? Acta Diabetol, 43:152-3.

Papanas N, Maltezos E. 2007. Growth factors in the treatment of diabetic foot ulcers: new technologies, any promises? Int J Low Extrem Wounds, 6:37-53.

Parkhouse N, Le Quesne PM. 1988. Impaired neurogenic vascular response in patients with diabetes and neuropathic foot lesions. $N$ Engl J Med, 318:1306-9.

Pecoraro R. 1991. Chronology and determination of tissue repair in diabetic lower extremity ulcers. Diabetes, 40:1305-13.

Persson U, Willis M, Ödegaard K, et al. 2000. The cost-effectiveness of treating diabetic lower extremity ulcers with becaplermin (Regranex): a core model with an application using Swedish cost data. Val Health, 3(Suppl I):S39-S46.

Petrova N, Edmonds M. 2006. Emerging drugs for diabetic foot ulcers. Expert Opin Emerg Drugs, 11:709-24.

Reiber GE, Vileikyte L, Boyko EJ, et al. 1999. Causal pathways for incident lower-extremity ulcers in patients with diabetes from two settings. Diabetes Care, 22:157-62.

Reiber GE, Ledoux WR. 2002. Epidemiology of diabetic foot ulcers and complications: evidence for prevention. In: Williams R, Herman W, Kinmoth AL, et al. (eds). The evidence bas for diabetes care. Chichester: Wiley, pp. 641-65.

Sibbald RG, Torrance G, Hux M, et al. 2003. Cost-effectiveness of becaplermin for nonhealing neuropathic diabetic foot ulcers. Ostomy Wound Manage, 49:76-84.

Singh N, Armstrong DG, Lipsky BA. 2003. Preventing foot ulcers in patients with diabetes. JAMA, 293:217-28.

Smiell JM. 1998. Clinical safety of becaplermin (rhPDGF-BB) gel. Am J Surg, 176(Suppl 2A):68S-73S.

Smiell JM, Wieman TJ, Steed DL, et al. 1999. Efficacy and safety of becaplermin (recombinant human platelet-derived growth factor-BB) in patients with nonhealing, lower extremity diabetic ulcers: a combined analysis of four randomized studies. Wound Rep Reg, 7:335-46.

Sumpio BE, Lee T, Blume PA. 2003. Vascular evaluation and arterial reconstruction of the diabetic foot. Clin Podiatr Med Surg, 20:689-708.

Steed DL. 1995. Clinical evaluation of recombinant human platelet-derived growth factor for the treatment of lower extremity diabetic ulcers. J Vasc Surg, 21:71-81.

Steed DL. 2004. Debridement. Am J Surg, 187:71S-74S.

Tentolouris N, Al-Sabbagh S, Walker MG, et al. 2004. Mortality in diabetic and nondiabetic patients after amputations performed from 1990 to 1995: a 5-year follow-up study. Diabetes Care, 27:1598-604.

van Houtum, Rauwerda JA, Ruwaard D, et al. 2004. Reduction in diabetesrelated lower-extremity amputations in the Netherlands: 1991-2000. Diabetes Care, 27:1042-6.

van Houtum W. 2005. Barriers to the delivery of diabetic foot care. Lancet, 366:1678-9.

Watkins PJ. 2003. The diabetic foot. BMJ, 326:977-9.

Wieman TJ, Smiell JM, Su Y. 1998. Efficacy and safety of a topical gel formulation of recombinant human platelet-derived growth factor-BB (Becaplermin) in patients with chronic neuropathic diabetic ulcers. A phase III randomized placebo-controlled double-blind study. Diabetes Care, 21:822-7.

Wieman TJ. 1998. Clinical efficacy of becaplermin (rhPDGF-BB) gel. Am J Surg, 176(Suppl 2A):74S-79S.

Wild S, Roglic G, Green A, et al. 2004. Global prevalence of diabetes: estimates for the year 2000 and projections for 2030. Diabetes Care, 27:1047-53. 